\title{
CROWDSOURCING LOST CULTURAL HERITAGE
}

\author{
E. K. Stathopoulou ${ }^{\mathrm{a} 1}$, A. Georgopoulos ${ }^{\mathrm{a}}$, G. Panagiotopoulos ${ }^{\mathrm{b}}$, D. Kaliampakos ${ }^{\mathrm{b}}$ \\ ${ }^{a}$ Lab. of Photogrammetry, School of Rural and Surveying Engineering, National Technical University of Athens - \\ 15780 Zografou Athens, Greece - (elliestath,drag)@ central.ntua.gr \\ ${ }^{\mathrm{b}}$ Lab. of Mining Engineering and Environmental Mining, School of Mining and Metallurgical Engineering, National Technical \\ University of Athens -15780 Zografou Athens, Greece - g.panag@ metal.ntua.gr
}

\section{Commission V, WG V/2}

KEY WORDS: SfM, 3D visualisation, Crowdsourcing, Cultural Heritage.

\begin{abstract}
:
Cultural Heritage all over the world is at high risk. Natural and human activities endanger the current state of monuments and sites, whereas many of them have already been destroyed especially during the last years. Preventive actions are of utmost importance for the protection of human memory and the prevention of irreplaceable. These actions may be carried out either in situ or virtually. Very often in situ preventive, or protective or restoration actions are difficult or even impossible, as e.g. in cases of earthquakes, fires or war activity. Digital preservation of cultural heritage is a challenging task within photogrammetry and computer vision communities, as efforts are taken to collect digital data, especially of the monuments that are at high risk. Visit to the field and data acquisition is not always feasible. To overcome the missing data problem, crowdsourced imagery is used to create a visual representation of lost cultural heritage objects. Such digital representations may be 2D or 3D and definitely help preserve the memory and history of the lost heritage. Sometimes they also assist studies for their reconstruction. An initiative to collect imagery data from the public and create a visual 3D representation of a recently destroyed stone bridge almost 150 years old is being discussed in this study. To this end, a crowdsourcing platform has been designed and the first images collected have been processed with the use of SfM algorithms.
\end{abstract}

\section{INTRODUCTION}

\subsection{Image based modelling}

Common image-based 3D modelling of the current state of a monument requires field data acquisition. Surveying, photogrammetry and laser scanning techniques can be combined to produce a full and accurate $3 \mathrm{D}$ model of the object. Such approaches cannot be applied in cases of sudden loss of cultural heritage objects due to a number of reasons such as fire, earthquakes, floods, looting, armed conflict, terrorism, attacks etc.

Standard photogrammetric or modern automated SfM (structure from motion) and MVS (multi-view stereo) algorithms make use of an object's images to reconstruct it in the 3D space (Ullman, 1979; Szeliski, 2010). The lack of images or other surveying data in lost cultural heritage objects has led to the use of random, unordered images acquired from the web. State of the art SfM algorithms are robust enough and deal sufficiently with such cases of extreme diversity among image content. SfM and MVS algorithms rely on accurate detection, extraction, description and matching of image features. This type of pipeline has developed immensely during the last years. A variety of studies have worked towards this direction developing efficient software. Photo Tourism (later called Bundler) is a navigation and exploitation interface that creates sparse 3D point clouds using random images collected from the web (Snavely et al, 2006). A few years later, another study continued working with web-retrieved images and overcame the problem of handling very large datasets (e.g. city photo collections) by using multi-core programming (Agarwal et al., 2011). Subsequent publications further extend the existing MVS algorithms to create dense point clouds implementing patch based methods and clustering (PMVS, Furukawa et al., 2010) or semi-global matching (SURE, Rothermel et al., 2011). Several GUI applications have been developed based on these algorithms and other tools, such as VisualSfM (Wu et al., 2011; $\mathrm{Wu}, 2013)$. Other free solutions are rather addressed to the scientific community like Apero/MicMac (Deseilligny and Clery, 2011). Commercial 3D modelling software like Agisoft Photoscan, Acute3D and Pix4D is also powerful enough and widely used in the field of cultural heritage. 3D modelling web services such as Photosynth, Arc3D or 123DCatch are also available, where the user acquires overlapping images of the object, uploads them on a remote server and finally a 3D model is derived and returned to the user.

\subsection{The traditional stone bridge of Plaka}

A variety of arched stone bridges exist in the Balkan area, built mainly in the $18^{\text {th }}$ and $19^{\text {th }}$ centuries or even earlier. Just in the Epirus region in northwestern Greece there are more than 250 magnificent examples of such historic structures spanning over the rivers and streams and bridging them with one to four arches. Such structures were built for pedestrian and animal passage, as the rivers did not allow easy crossing, especially during winter (Leftheris et al., 2006). In the pre-industrial era, the main structural material in the Balkan region was the local stone. In Epirus, limestone and wood was commonly used by specialized technicians for such purposes. Stone bridges

\footnotetext{
${ }^{1}$ Corresponding author
} 
constituted a wide trail network for communication and transportation in the whole Balkan area.

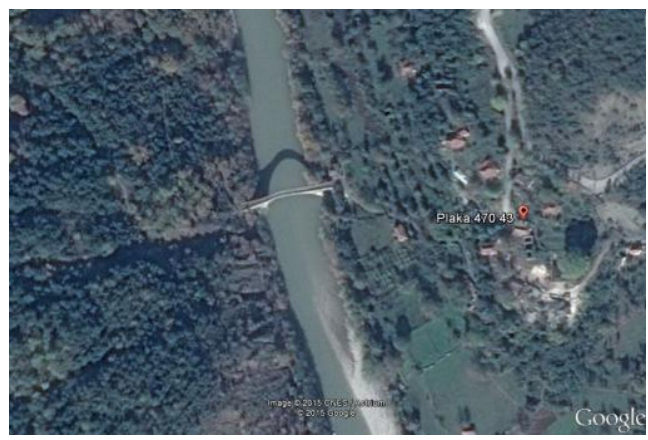

Figure 1: The Plaka Stone Bridge

The stone bridge of Plaka over river Arachthos (Figure 1) was a representative example of the aforementioned monuments. It was built in 1866 by local Greek stonemasons in order to facilitate transportation and trade needs (http://www.petrinagefiria.uoi.gr/). It was the widest stone bridge in the area of Epirus with 40 meter span and the biggest single-arch bridge in the Balkans with a height of 20 meters (Figure 2). Next to the main arch, there were two smaller ones 6 meters wide, the so-called relief arches.

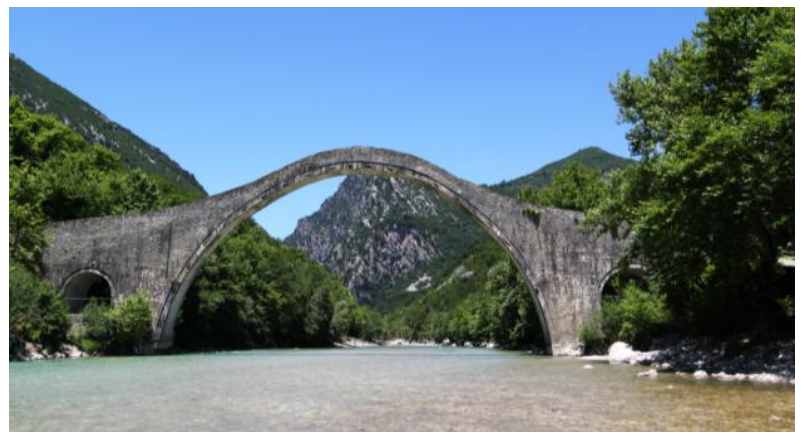

Figure 2: Plaka stone bridge.

Apart from its significant size and age, the stone bridge of Plaka was a renowned stone bridge in Greece because of its emblematic historic meaning. Firstly, it was the border between free Greece and the occupied part of Greece by the Ottoman Empire between 1881 and 1912. During World War II the bridge was bombed by the German army with partial damages. At the same period, representatives of the various armed groups of Greek Resistance signed the Treaty of Plaka on this very bridge. A finite element analysis (static and dynamic) of Plaka bridge was carried out by Leftheris et al., (2006), investigating the deformations, the movements and mentioning the risks from possible earthquakes.

On the $1^{\text {st }}$ of February 2015 , the central section of the bridge's unique arch collapsed due to extreme weather conditions namely massive flash floods caused on by prolonged heavy rainfall. Most of the collapsed parts, especially some of the massive ones, lie in the river area near the abutments that remain intact (Figure 3). National Technical University of Athens has immediately initiated voluntary actions to aid in the eventual reconstruction of the stone bridge. In this project an interdisciplinary group of scientists and engineers will contribute, such as architects, civil engineers, surveyors, photogrammetry engineers, computer scientists, material engineers etc. The exact reasons that led to the destruction are currently under investigation in order to take the right measures to protect other similar stone bridges equally endangered.

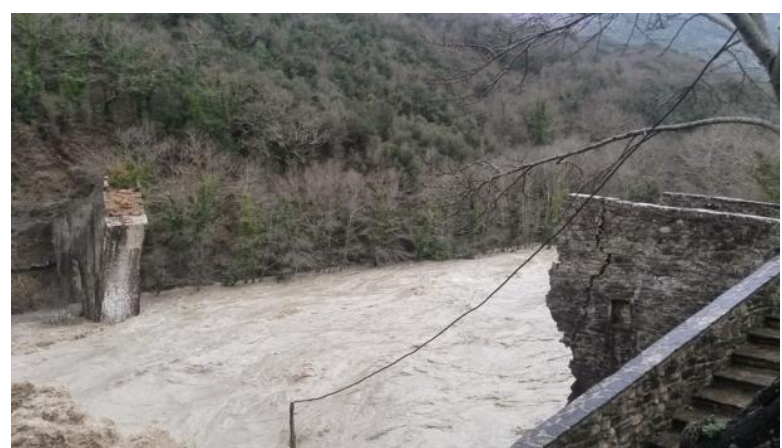

Figure 3: The remains of the bridge after destruction (http://epirusgate.blogspot.gr/2015/02/blog-post_32.html)

The type of eventual reconstruction in the current study is under discussion. Before the implementation of any actions, a thorough geometric documentation is necessary, as clearly dictated by the Venice Charter (1964). For that purpose the Laboratories of Photogrammetry and General Geodesy undertook two tasks (a) to produce digital three dimensional drawings from a documentation study conducted in 1984 using traditional surveying techniques (Karakosta et al., 1984) and (b) to produce a textured three dimensional model of the Plaka Stone Bridge in order to geometrically document its shape and size before the collapse. This 3D model would be produced from existing images taken by visitors of the bridge over the years. These documentation products will form the basis for any eventual reconstruction study. Unfortunately, no earlier photogrammetric documentation is known to exist so far.

\section{RELATED WORK}

Modern photogrammetry and computer vision techniques manage to create useful and accurate 3D models of objects of almost any size and shape, by combining robust algorithms and powerful computers. Multiple images depicting the object from different viewpoints are needed and the so-called SfM and MVS procedures are implemented. These images do not necessarily need to have been captured by calibrated cameras, though. Compact or even mobile phone cameras can also be used. Moreover, capturing geometry is nowadays flexible, in contrast with the traditional strict stereo-normal case of the past. A variety of recent studies are examining the creation of $3 \mathrm{D}$ models of cultural heritage objects and sites with the use of SfM algorithms (Remondino et al., 2012; Kersten and Lindstaedt, 2012; Barsanti and Guidi, 2013; Santagati et al., 2013).

However, few projects, many of them EU funded, make use of data available in the web for such a purpose. Some recent studies are dealing with the 4D (space-time) virtual reconstruction of Cultural Heritage objects using web-retrieved images (Kyriakaki et al., 2014; Santos et al. 2014; Makantasis et al., 2014). An approach for diachronic virtual reconstruction of lost heritage based on historical information integrated with real metric data of the remains was proposed by Guidi et al., (2011).

HeritageTogether project is an initiative that creates 3D models and metadata of standing stones, cairns and other heritage sites of Wales aiming to engage the local community in recording prehistoric heritage and providing freely accessible data (Karl et al., 2014). An online photogrammetry tool was developed, the 
public is asked to explore the sites, capture appropriate photos and upload them to the server.

\section{CROWDSOURCING}

For image-based virtual reconstruction many images from different points of view are required. As already implemented in similar cases in the past, the contribution of people that have visited the area for tourism or other reasons and have taken pictures was sought (Oomen \& Aroyo, 2011). However, this time a metric product was produced with the use of previous study's results (Karakosta et al., 1984).

The stone bridge of Plaka is a significant monument within the area of Epirus, lacks however recognition in the rest of Greece compared to other cultural heritage sites. Therefore, fewer visitors have explored the area and photographed the monument, especially in the digital imaging era. Thus, searching by keywords and other location based queries in the web search engines returns few results and most of them are uploaded in low resolution. Wrong or inaccurate labelling is also a challenge. Radiometric low quality or post-processed imagery (compression, filters etc.) often results in such queries, prohibiting their use for reliable $3 \mathrm{D}$ modelling.

Crowdsourcing has become a very popular tool to acquire image and geographic content, among other data (Goodchild 2007, Sylaiou et al. 2013). A system is defined as a crowdsourcing one, "if it enlists a crowd of humans to help solve a problem defined by the system owners" (Doan et al., 2011). In this case study, crowdsourcing serves as a method to acquire the large number of images (or videos) needed for the project as well as to guide the potential contributors according to the needs (e.g. specific viewpoints needed). The key aspects of the project concerning crowdsourcing information can be summarized as follows:

- The project has a time limit

- The contribution of the users is of one type of content, i.e. images or video sequences.

- Special information (metadata) about the viewpoint of the images, the equipment used or the time taken could be useful.

To provide a suitable framework for the above, a website has been developed using the Drupal CMS (http://gefyriplakas.ntua.gr/) (Figures 4, 5). Drupal is a Content Management System (CMS) with proper functions for community websites and has been used for educational and research crowdsourcing purposes (Kaliampakos et al., 2015; Munoz-Torres et al., 2011). More specifically, the website developed includes five sections: (a) a news and announcements page, (b) a general info page, (c) a submit content (images) page, (d) a submit page for volunteers and (e) a blog page. To collect the images, the "submit images" page is the only section utilized, since it also provides the required information to the contributors. The technical specifications of the webpage are:

- It is available only in Greek language. This addresses the fact that the bridge is a highly localized symbol and so it is expected that persons with connections to the surrounding area or Greek visitors would be more able to contribute.

- Since the time frame was short, the promotion of the website could not be supported only by web search

engines (which take a considerable amount of time and effort to work properly for the owners' needs). Therefore, various social media as well as local blogs and news websites, a fact that adds to the previous comment about the localization of the event, have been used to make the website known to the public.

- The submission form for the users is fairly simple. It only requires a short description of the images, the actual image files to be uploaded and an optional extended description. Furthermore, the submit form is available to the anonymous users, since there is no need for any sort of authentication. Anonymous contribution, without any form of evaluation, could be a serious issue in crowdsourcing, however it is not posing an obstacle for the purposes of this project. The content (images) analysis can only be performed by the experts with the right tools available. A primitive sorting of the images related to their type, size, date taken, etc. could be done by software with no intervention from the user or the analyst. Since video files are relatively large in size, alternate methods were also selected to acquire them (after contact with the contributor), in order to avoid complications or user discomfort with the upload procedure. Moreover, the short time frame means a smaller amount of spamming attacks from internet bots. Hence, authentication or a more systematic form was avoided to decrease the load for the users and increase their willingness to contribute, without resulting to additional effort for the researchers.

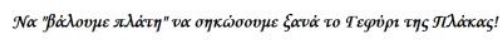
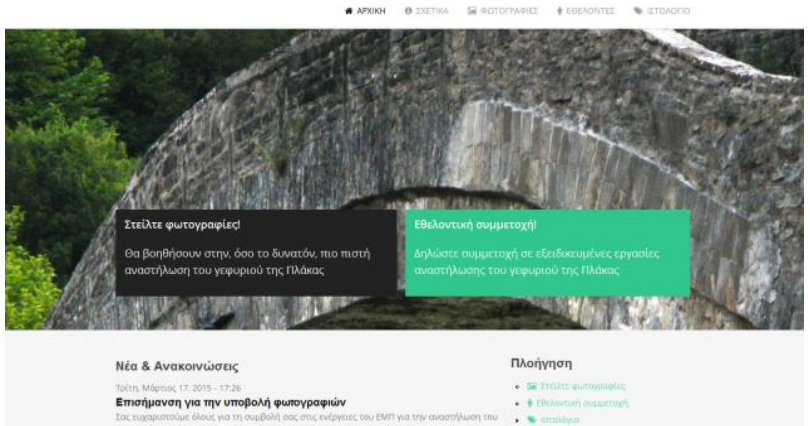

Emonipavon via mivuroporti quroypaquiv

Figure 4: Home page of the crowdsourcing webpage.

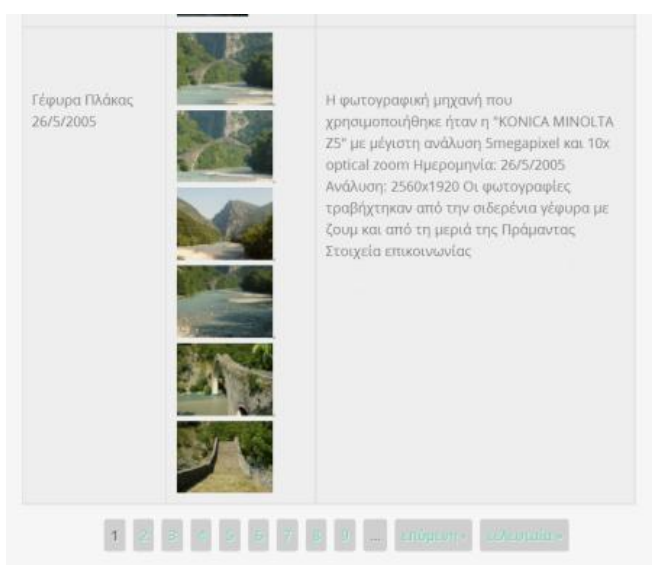

Figure 5: Image submission example. 
Within the first month of its operation the website has been visited around 2800 times (Table 1). More than 470 images were uploaded to the platform during these sessions by more than 130 contributors. Apart from the uploaded content, approximately 200 images and 15 videos were collected through other means, mainly by ordinary mail delivery, by contacting the contributors.

Table 1: Statistical data during the first month.

\begin{tabular}{|c|c|}
\hline approx. no. of visits & 2800 \\
\hline image uploads & 470 \\
\hline approx. no. contributors & 130 \\
\hline data by other means (CD, DVD etc.) & 200 \\
\hline
\end{tabular}

\section{METHODOLOGY AND RESULTS}

The majority of the collected images are generally of high resolution, acceptably focused and without immense perspective or optical distortions. Nevertheless, in crowdsourcing applications the data may not meet the requirements of the scope for which they were collected. In this case study the authors have had to cope with some special challenges. A great percentage of the images were acquired from a viewpoint very close to the object and cannot, thus, be registered to the rest using the available algorithms. Large illumination variations due to natural light (bright sunshine, clouds, shadows, dusk light etc.) appear in several photos. Apart from that, the images that are suitable for the specific purpose of the project show significant variations on the bridge's surface due to seasonal effects. During summer months the stones are dry, in winter they appear darker and wet, with black grey crust and growing grass, thus complicating the location of point correspondences. Trees and other natural or human obstacles hinder important information. The geometry of the bridge, which is almost symmetrical, makes it difficult to distinguish between the north and the south façade. The majority of the collected photos were taken facing upstream and mainly from the east riverside due to landscape inaccessibility (Figure 6). This causes gaps and difficulties for the algorithm to converge to a stable geometry. After a thorough and careful sorting, it was established that less than 60 images fulfil the needs of the project in terms of viewpoint, image resolution, lighting conditions, occlusions etc., which corresponds to $10 \%$ of the total contributions.

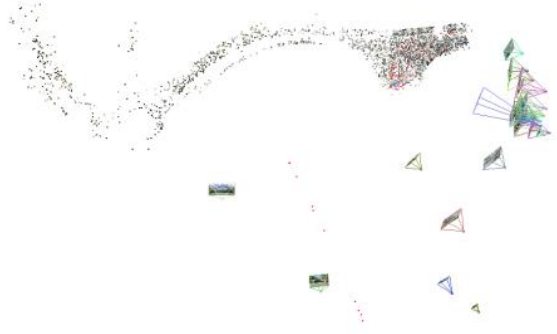

Figure 6: Viewpoint distribution.
The selected data have been processed using commercial as well as free software. VisualSfM is a free GUI application for 3D reconstruction that implements SfM and PMVS along with other tools (Wu, 2007; Wu et al., 2011; Wu, 2013; Furukawa and Ponce, 2010, Furukawa et al., 2010). In our case study, the dense point cloud was produced by 51 images (Figure 7).

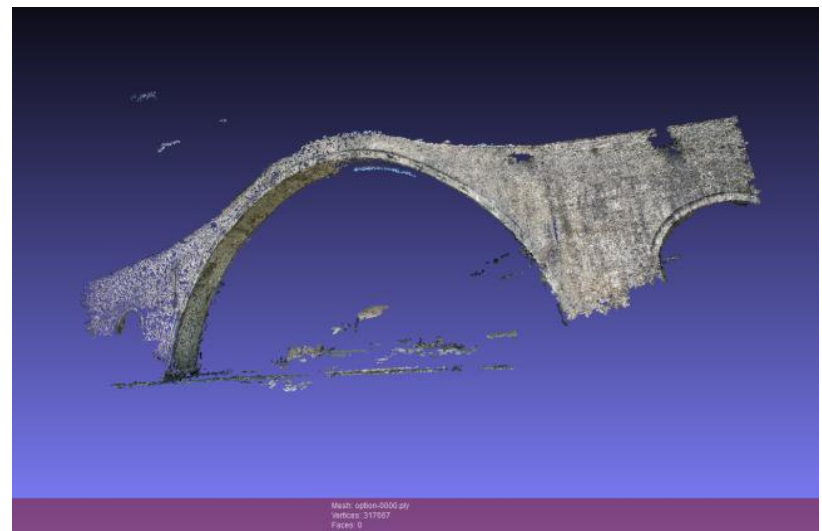

Figure 7: Dense point cloud after PMVS software (VisualSfM) -51 images.

In order to improve the results, a masking procedure was applied on the images while processed in Agisoft PhotoScan. Therefore, background elements that are subjected to temporal changes and obstacles (people, trees, mountains, sky etc.) have been excluded during photo alignment. This results to less noisy dense point clouds (Figure 8). A mesh has also been created out of this dense point cloud, followed by the texturing procedure (Figure 9).

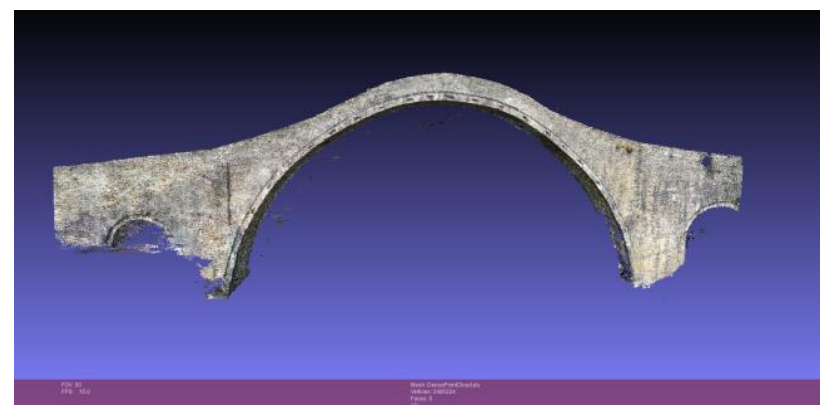

Figure 8: Dense point cloud produced in Agisoft PhotoScan 56 images.

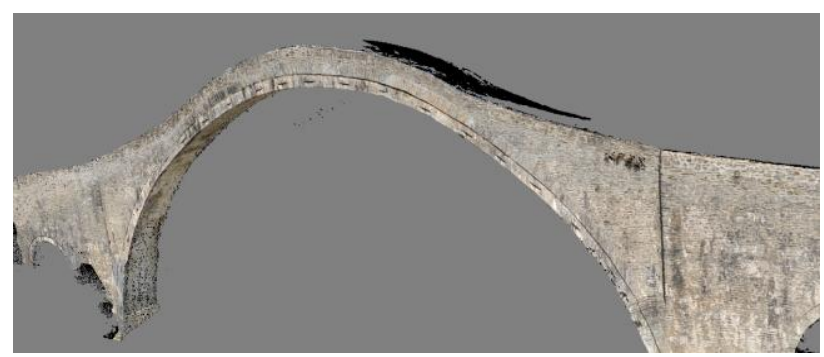

Figure 9: A view of the textured mesh created in Agisoft PhotoScan

The final model was integrated with the existing 3D surveying measurements of 1984 (Karakosta et al., 1984) in order to constrain its scale and accurately document the geometry of the bridge as it was before the collapse. 


\section{CONCLUSIONS}

The progress so far of an on-going project that aims to produce $3 \mathrm{D}$ textured models of the stone bridge of Plaka that suffered sudden loss has been presented. As data for a complete 3D reconstruction do not exist, a 3D representation of the bridge using crowdsourced images is the only way to preserve the memory and help towards its eventual reconstruction. A crowdsourcing platform has been designed and commercial as well as free 3D reconstruction software has been used to this end. Preliminary results demonstrate the robustness of the state of the art algorithms that are able to register together images of high diversity and create usable $3 \mathrm{D}$ models. These preliminary models may not be complete yet, but serve adequately as a base for future work, visualisation and educational purposes. It is also estimated that further exploitation of more images uploaded will result to a usable geometric documentation record for the eventual reconstruction.

It should be stressed that the wide promotion of the $3 \times 3$ Rules proposed by CIPA (Waldhaeusl and Ogleby 1994) and revised in 2013, available at the relevant webpage (www.cipa.icomos.org) would ensure the existence of more useful images and related metadata for the Plaka Stone Bridge, as the public would be more aware of the eventual future significance of their souvenir images. This may be useful in the future for other monuments in similar situations.

In the future, frames from the submitted videos will be extracted and added as input to the SfM procedure together with new image contributions. Image rectification techniques will be investigated for the visualisation of the other façade of the bridge. Further accuracy assessments of the produced models will also follow.

\section{ACKNOWLEDGEMENTS}

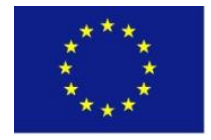

This project has received funding from the European Union's Seventh Framework Programme for research, technological development and demonstration under grant agreement no 608013, titled "ITN-DCH: Initial Training Network for Digital Cultural Heritage: Projecting our Past to the Future."

\section{REFERENCES}

Agarwal, S., Furukawa, Y., Snavely, N., Simon, I., Curless, B., Seitz, S. M., Szeliski, R. (2011). Building Rome in a day. Communications of the ACM, 54(10), 105-112.

Barsanti, S. G., Guidi, G. (2013). 3D digitization of museum content within the 3D-ICONS project. ISPRS Ann. Photogramm. Remote Sens. Spatial Inf. Sci, II-5 W, 1, 151-156.

Deseilligny, M. P., Clery, I. (2011). Apero, an open source bundle adjusment software for automatic calibration and orientation of set of images. ISPRS-International Archives of the Photogrammetry, Remote Sensing and Spatial Information Sciences, 38, 5 .

Doan, A., Ramakrishnan, R., Halevy, A. Y. (2011). Crowdsourcing systems on the world-wide web. Communications of the ACM, 54, 86-96.
Furukawa, Y., Ponce, J. (2010). Accurate, dense, and robust multiview stereopsis. Pattern Analysis and Machine Intelligence, IEEE Transactions on, 32(8), 1362-1376.

Furukawa, Y., Curless, B., Seitz, S. M., Szeliski, R. (2010). Towards internet-scale multi-view stereo. In Computer Vision and Pattern Recognition (CVPR), 2010 IEEE Conference on (pp. 1434-1441). IEEE.

Goodchild, M., 2007. Citizens as Sensors: The World of Volunteered Geography. Geo Journal 69, pp. 211-221.

Guidi, G., Russo, M. (2011). Diachronic 3D reconstruction for lost Cultural Heritage. ISPRS-International Archives of the Photogrammetry, Remote Sensing and Spatial Information Sciences, 3816, 371-376.

Kaliampakos, D., Benardos, A., Mavrikos, A., Panagiotopoulos, G. (2015). The Underground Atlas Project. Tunnelling and Underground Space Technology, (accepted for Publication).

Karakosta, E., Papanagiotou, B., Tragaris, N., Chatzigeorgiou, Th., Arampatzi, O., Doggouris, S., Mpalodimos, D-D., (1984). Plaka Bridge: Survey- Check for vertical deformations, Diploma Thesis, National Technical University of Athens.

Karl, R., Roberts, J., Wilson, A., Möller, K., Miles, H. C., Edwards, B., Tiddeman, B., Labrosse, F., Trobe-Bateman, E. L. (2014). Picture This! Community-Led Production of Alternative Views of the Heritage of Gwynedd. Journal of Community Archaeology \& Heritage, 1(1), 23-36.

Kersten, T. P., Lindstaedt, M. (2012). Image-based low-cost systems for automatic 3D recording and modelling of archaeological finds and objects. In Progress in cultural heritage preservation (pp. 1-10). Springer Berlin Heidelberg.

Kyriakaki, G., Doulamis, A., Doulamis, N., Ioannides, M., Makantasis, K., Protopapadakis, E., Hadjiprocopis, A., Wenzel, K., Fritsch, D., Klein, M., Weinlinger, G. (2014). 4D Reconstruction of Tangible Cultural Heritage Objects from Web-Retrieved Images. International Journal of Heritage in the Digital Era, 3(2), 431-452.

Leftheris, B.P., Stavroulaki, M.E., Sapounaki, A.C., Stavroulakis, G.E., (2006). Computational Mechanics for Heritage Structures, WIT Press, Southampton.

Makantasis, K., Doulamis, A., Doulamis, N., Ioannides, M., \& Matsatsinis, N. (2014). Content-Based Filtering for Fast 3D Reconstruction from Unstructured Web-Based Image Data. In Digital Heritage. Progress in Cultural Heritage: Documentation, Preservation, and Protection (pp. 91-101). Springer International Publishing.

Munoz-Torres, M. C., Reese, J. T., Childers, C. P., Bennett, A. K., Sundaram, J. P., Childs, K. L., Anzola, J. M., Milshina, N., Elsik, C. G. (2011). Hymenoptera Genome Database: integrated community resources for insect species of the order Hymenoptera. Nucleic acids research, 39, D658-D662.

Oomen, J., \& Aroyo, L. (2011). Crowdsourcing in the Cultural Heritage Domain: Opportunities and Challenges. In: Proceedings of the 5th International Conference on Communities and Technologies. 19 June -2 July, Brisbane (Australia). 
Remondino, F., Del Pizzo, S., Kersten, T. P., Troisi, S. (2012). Low-cost and open-source solutions for automated image orientation-A critical overview. In Progress in cultural heritage preservation (pp. 40-54). Springer Berlin Heidelberg.

Rothermel, M., Wenzel, K., Fritsch, D., \& Haala, N. (2012, December). Sure: Photogrammetric surface reconstruction from imagery. In Proceedings LC3D Workshop, Berlin (pp. 1-9).

Santagati, C., Inzerillo, L., Di Paola, F. (2013). Image-based modeling techniques for architectural heritage 3D digitalization: Limits and potentialities. International Archives of the Photogrammetry, Remote Sensing and Spatial Information Sciences, 5(w2), 555-560.

Santos, P., Serna, S. P., Stork, A., Fellner, D. (2014). The Potential of 3D Internet in the Cultural Heritage Domain. In $3 D$ Research Challenges in Cultural Heritage (pp. 1-17). Springer Berlin Heidelberg.

Snavely, N., Seitz, S. M., \& Szeliski, R. (2006, July). Photo tourism: exploring photo collections in 3D. In ACM transactions on graphics (TOG) (Vol. 25, No. 3, pp. 835-846). ACM.

Sylaiou, S., Basiouka, S., Patias, P., \& Stylianidis, E. (2013). The volunteered geographic information in archaeology. ISPRS Annals of the Photogrammetry, Remote Sensing and Spatial Information Sciences, 301-306.

Szeliski, R. (2010). Computer vision: algorithms and applications. Springer Science \& Business Media.

Ullman, S. (1979). The interpretation of structure from motion. Proceedings of the Royal Society of London, B-203:405-426.

Waldhäusl, P., Ogleby, C. L. (1994). 3 x 3 rules for simple photogrammetric documentation of architecture. International Archives of Photogrammetry and Remote Sensing, 30, 426-429.

Wu, C. (2013, June). Towards linear-time incremental structure from motion. In $3 D$ Vision-3DV 2013, 2013 International Conference on (pp. 127-134). IEEE.

Wu, C., Agarwal, S., Curless, B., Seitz, S. M. (2011, June). Multicore bundle adjustment. In Computer Vision and Pattern Recognition (CVPR), 2011 IEEE Conference on (pp. 30573064). IEEE.

Wu, C., "SiftGPU: A GPU implementation of Scale Invariant Feature Transform (SIFT)", http://cs.unc.edu/ ccwu/siftgpu, 2007. 